\title{
Cancer Antigen 72-4 for the Monitoring of Advanced Tumors of the Gastrointestinal Tract, Lung, Breast and Ovaries
}

\author{
ANUSIYANTHAN ISAAC MARIAMPILLAI ${ }^{1}$, JOSEPHINE PINEDA DELA CRUZ ${ }^{1}, \mathrm{JASON} \mathrm{SUH}^{2}$, \\ ABIRAMI SIVAPIRAGASAM ${ }^{3}$, KYLE NEVINS $^{4}$ and ALEXANDER A. HINDENBURG ${ }^{1}$ \\ ${ }^{1}$ Department of Hematology and Oncology, NYU Winthrop Hospital, Mineola, NY, U.S.A.; \\ ${ }^{2}$ Department of Hematology and Oncology, Valley-Mount Sinai Comprehensive Cancer Care, Paramus, NJ, U.S.A.; \\ ${ }^{3}$ Department of Medicine, SUNY Upstate University Hospital, Syracuse, NY, U.S.A.; \\ ${ }^{4}$ Northwell Health Laboratories, New York, NY, U.S.A.
}

\begin{abstract}
Background: Cancer antigen CA72-4 is a tumor marker found to be elevated in a variety of human adenocarcinomas. Using the DRG TM-CA72-4, we quantified the elevation of CA72-4 compared to current United States Food And Drug Administration-approved tumor markers in various cancer types. Materials and Methods: We conducted a prospective, single-center study enrolling 96 patients between March 2013 and August 2016 with different locally advanced, unresectable or metastatic cancer known to express CA72-4. Quantification of CA72-4 was performed according to the manufacturer's instructions using the DRG TM-CA72-4 enzyme-linked immunosorbent assay kit and the positivity rates were calculated. Results: CA72-4 expression varied with tumoral site of origin, with the highest positivity rates found in pancreatic and ovarian malignancies. Correlation with clinical activity was also noted in some patients. Conclusion: CA72-4 may have a potential role as an adjunct to conventional biomarkers in disease monitoring of pancreatic, ovarian and colorectal carcinomas.
\end{abstract}

In the management of metastatic and recurrent cancer, it is vital to assess response to antitumor therapy. The most commonly used methodology is by serial measurement of tumor size on physical examination or imaging studies employing the response evaluation criteria in solid tumors (RECIST) criteria. As an adjunct to direct measurement of lesions, several tumor

This article is freely accessible online.

Correspondence to: Alexander A. Hindenburg, MD, NYU Winthrop Hospital, 200 Old Country Rd, Suite 450, Mineola, NY 11501, U.S.A. Tel: +1 5166639500, e-mail: ahindenburg@nyuwinthrop.org

Key Words: CA72-4, Gastrointestinal cancer, tumor marker, ovarian cancer, pancreatic cancer. markers including carcinoembryonic antigen (CEA), cancer antigen 19-9 (CA19-9) and cancer antigen 125 (CA125) have obtained United States Food and Drug Administration (FDA) approval for the monitoring of various gastrointestinal and gynecologic malignancies. These tumor markers along with cancer antigen 27-29 (CA27-29) used in the monitoring of breast cancer are proteins shed by cancer cells and are readily measured in the laboratory using antibodies.

The utility of serial measurement of CA19-9, CEA, and CA125 in predicting treatment response in pancreatic, colon and ovarian cancer has been validated in multiple studies (14). Frequent serial measurements can easily be obtained and have the potential of alerting the clinician to the need for timely assessment of a patient for treatment failure, allowing for earlier intervention. In addition, tumor markers may at times have greater accuracy in assessing response since imaging studies using RECIST criteria are not totally reliable as they do not always differentiate viable tumor from residual fibrosis or scarring. Nevertheless, their usefulness in tumor monitoring has been limited by their inconsistent and variable elevation in various malignancies, the need for a relatively large tumor burden to cause an elevation, frequent false-positive elevations in non-malignant conditions, and by lack of conviction by the oncological community to accept an increase or decrease in the tumor marker as a surrogate for disease progression or response. Thus, there remains and unmet need for development of new biomarkers for assessment of tumor burden and response to therapy. While rapidly-evolving research utilizing analysis of circulating tumor DNA as well as proteomics is underway, we continue to rely on traditional techniques such as measuring of concentrations of abnormal proteins shed by various cancer types.

In addition to the conventional tumor markers CEA, CA27-29, CA19-9 and CA125 there is another tumor marker, tumor-associated glycoprotein 72 (TAG-72) 
developed years ago used world-wide which never gained US FDA approval. This is a $48-\mathrm{kDa}$ mucin-like glycoprotein complex, identified with the monoclonal antibody B72.3, a murine antibody raised against a membrane-enriched fraction from a human breast carcinoma liver metastasis (5). CA72-4 antigen is an antigenic determinant of the TAG-72 glycoprotein, which is also recognized by the B72.3 and CC- 49 monoclonal antibodies (6). This antigen has been found in a variety of human adenocarcinomas including colorectal, gastric, ovarian, breast, and lung, however, it is rarely expressed in benign and normal adult tissues (7-9).

While CA125, CEA and CA19-9 currently are standard tumor markers for ovarian, gastrointestinal (i.e. stomach, colon and small bowel) and pancreatic cancer, respectively, CA72-4 remains a potentially superior biomarker for these types of cancer.

The DRG TM CA72.4 enzyme-linked immunosorbent (ELISA) kit is a solid-phase sandwich assay, utilizing CC49 antibody, developed by DRG International (New Jersey, USA) and validated as a standalone assay to be employed in the individual hospital and laboratory setting. Using the DRG TM CA72-4 ELISA assay, the current study aimed to i) quantify the rate of elevation of the tumor marker CA724 in each cancer type compared to the rate of elevation of other current FDA-approved tumor biomarkers, and ii) correlate levels of CA72-4 to clinical outcomes in patients with measurable disease.

\section{Materials and Methods}

Study participants. We conducted a prospective, single-center study involving 96 patients with different histologically confirmed, primary locally advanced or metastatic cancer with measurable disease that were known to express CA72-4 (Figure 1). Patients were enrolled between March 2013 and August 2016. Informed written consent was obtained from all individuals prior to enrollment in the study and the study was approved by the Institutional Review Board (\#12040).

Blood serum was collected from patients undergoing treatment at 3- to 4-week intervals for CA72-4 measurement along with other FDA-approved markers for site-specific malignancies. Patients with the following characteristics were included in the study: 18 years of age or older, de novo or previously diagnosed metastatic or recurrent non-surgically resectable carcinomas of the ovaries, non-squamous lung carcinoma, adenocarcinoma of the pancreas, stomach, breast, gallbladder, biliary, ampullary, colorectal, gastric, gastro esophageal junction or esophagus (Table I). Only patients with a detectable level of CA72-4 at enrollment or who developed a detectable level during the first four consecutive blood draws were followed in the study. Patients with more than four consecutive negative CA72-4 determinations were excluded from subsequent CA72-4 blood draws, and classified in the CA72-4-negative group but were followed clinically and with established tumor markers as correlates based on clinical indication (e.g. CA19-9 for pancreas, CA27-29 for breast and CEA for gastric cancer).
Table I. Demographics and enrollment data.

\begin{tabular}{lccc}
\hline Variable & \multicolumn{2}{c}{ CA72-4 status $(>0.8 \mathrm{U} / \mathrm{ml})$} & \\
\cline { 2 - 3 } & Positive & Negative & \\
\hline $\begin{array}{l}\text { Male } \\
\mathrm{n}(\%)\end{array}$ & $22(33)$ & $12(40)$ & 0.53 \\
Female & & & \\
$\mathrm{n}(\%)$ & $44(67)$ & $18(60)$ & \\
Total & $66(100)$ & $30(100)$ & \\
Age (years) & & & \\
Median & 65.5 & 65.0 & \\
Mean & 64.7 & 66.6 & \\
\hline
\end{tabular}

Quantification of CA72-4 in blood serum. Briefly, whole blood was collected via venipuncture and allowed to clot. Serum was separated by centrifugation at room temperature within $1 \mathrm{~h}$ collection or sooner and samples frozen at $-20^{\circ} \mathrm{C}$ for further processing. Quantification of CA72-4 was performed using the DRG TM-CA 72-4 ELISA kit according to the manufacturer's instructions. A fivepoint calibration curve was generated for each ELISA plate, with both a low and high control included in each run to ensure reliability of the assay results. The limit of detection of the assay was $0.8 \mathrm{U} / \mathrm{ml}$. Calibrators, controls, and each patient sample were tested in duplicate on the ELISA plate in order to calculate the within-run mean, standard deviation, and coefficient of variance for each of the patient samples. Twenty microliters of appropriate sample (calibrator, control, or patient) was added to each well on the antigen-coated plate, placing sample duplicates horizontally next to their matched pair. After all samples to be tested were transferred to the plate, $100 \mu \mathrm{l}$ of enzyme conjugate was added to each well using a multi-channel pipette. Sample and conjugate were mixed within each well for a minimum of $10 \mathrm{sec}$, followed immediately by 2 -h incubation at room temperature. At the completion of the first incubation period, the plate was washed five times with $400 \mu \mathrm{l}$ of diluted wash solution per well. After washing of the plate, 100 $\mu l$ of substrate was added to each well and plates were incubated further for $30 \mathrm{~min}$ at room temperature to allow for color development within the wells. At the end of the second incubation period, $100 \mu \mathrm{l}$ of stop solution was added to each well and the absorbance was read on a spectrophotometer at $450 \mathrm{~nm}$. Results were calculated using a 4-parameter Marquardt curve fit based on the mean absorbance reading per sample pair. Positivity was defined as a value greater than $0.8 \mathrm{U} / \mathrm{ml}$ or $4.0 \mathrm{U} / \mathrm{ml}$ based on systematic review of prior studies (10-12). Established levels of tumor markers CEA, CA19-9, CA27-29 and CA125 were determined according to existing commercial laboratory methods.

\section{Results}

A total of 96 patients were enrolled in the study over a 4-year period. The median age of patients with positive and negative CA72-4 assays were 65.5 versus 65.0 years, respectively $(p=0.34)$. Of all CA72-4-positive patients, $33 \%$ were male, and of the negative patients, $40 \%$ were male $(p=0.53)$. 


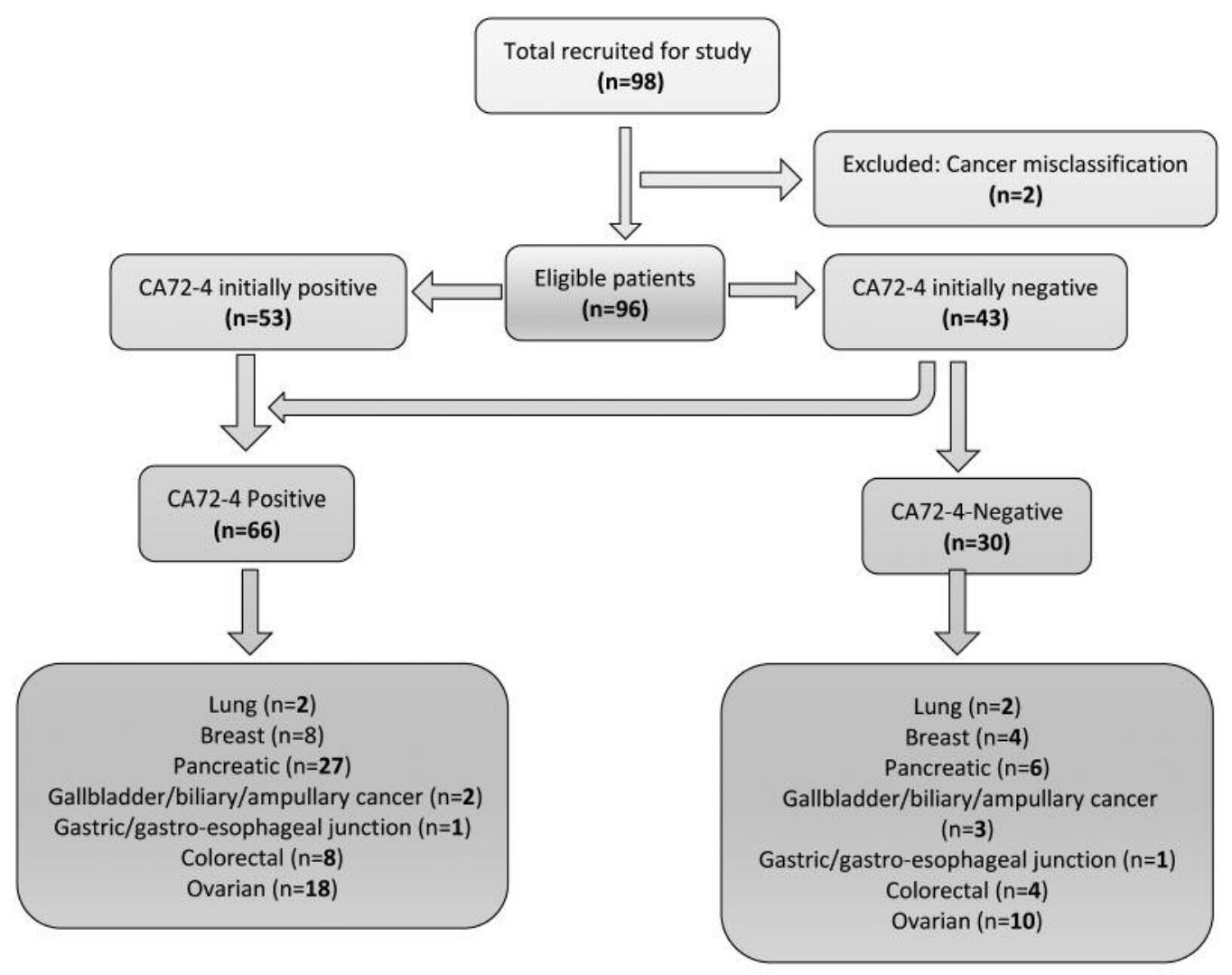

Figure 1. Study design.

Using $0.8 \mathrm{U} / \mathrm{ml}$ as a cut-off for positivity for CA72-4 in our assay, we found that $55.2 \%$ (53/96) of the patients were positive and $44.8 \%$ (43/96) were negative for this tumor marker at the time of enrollment. Using the previously reported level of 4 $\mathrm{U} / \mathrm{ml}$ as the cut-off for positivity reduced the positivity rate to $33.3 \%(32 / 96)$ and increased negativity to $66.7 \%(64 / 96)$ at enrollment. Using $0.8 \mathrm{U} / \mathrm{ml}$ as a cut-off, $30.2 \%$ (13/43) of the CA72-4-negative patients developed detectable levels of CA724 in their serum during the initial four blood draws versus $16 / 64$ (25.0\%) using $4 \mathrm{U} / \mathrm{ml}$ as a cut-off.

Site-specific data for each cut-off are presented in Table II. Using $0.8 \mathrm{U} / \mathrm{ml}$ as a cut-off, the highest rate of positivity for CA72-4 was found in pancreatic cancer $(82 \%, 27 / 33)$, while currently established FDA markers such as CA19-9 were positive in $84.8 \%$ (28/33) of patients while using $4 \mathrm{U} / \mathrm{ml}$, this rate dropped to $58 \%$ (19/33). Lowest rates of positivity did not differ when using $0.8 \mathrm{U} / \mathrm{ml}$ or $4 \mathrm{U} / \mathrm{ml}$ as cut-off: $1 / 2$ patients with gastric/gastroesophageal junction tumors, $2 / 5$ with gallbladder/biliary tract tumors, while CA72-4 positivity in lung cancer decreased from $2 / 4$ for $0.8 \mathrm{U} / \mathrm{ml}$ to $0 / 4$ for $4 \mathrm{U} / \mathrm{ml}$, although very few patents were enrolled with these types of cancer. Other sites of high positivity included ovarian at
$64.3 \%(18 / 28)$ for $0.8 \mathrm{U} / \mathrm{ml}$ versus $57 \%$ (16/28) for $4 \mathrm{U} / \mathrm{ml}$ cut-offs, however, this included both mucinous and nonmucinous subtypes. Total positivity for CA72-4 amongst all patients across all categories was $68 \%(66 / 96)$ at $0.8 \mathrm{U} / \mathrm{ml}$ and $50 \%$ (48/96) for $4 \mathrm{U} / \mathrm{ml}$.

\section{Discussion}

Tumor biomarkers play a crucial role in monitoring of response to therapy and in post-treatment surveillance of various gastrointestinal and gynecological malignancies (13). While the clinical value of FDA-approved tumor markers such as CEA, CA19-9 and CA125 has been established, adequate data to support FDA approval of CA72-4 as a potential biomarker are lacking and its measurement is only considered experimental and investigational. Here, we briefly review the nature of currently validated tumor markers and discuss the potential role of CA72-4 within the armamentarium.

CEA. A 180-kDa oncofetal cell-surface-anchored glycoprotein, CEA was first isolated in 1965 by investigators at McGill University from human colon tissue extracts (14). The 
Table II. Disease distribution data for CA72-4 using 0.8 and 4 U/ml as cut-offs for positivity.

\begin{tabular}{|c|c|c|c|c|c|c|}
\hline \multirow[b]{2}{*}{ Ca72-4 analysis* } & \multicolumn{2}{|c|}{ CA72-4, n (\%) } & & & & \\
\hline & $\begin{array}{l}\text { Cut-off- } \\
(>0.8 \mathrm{U} / \mathrm{ml})\end{array}$ & $\begin{array}{l}\text { Cut-off- } \\
(>4 \mathrm{U} / \mathrm{ml})\end{array}$ & & & & \\
\hline Initially positive & $53 / 96(55.2 \%)$ & $32 / 96(33.3 \%)$ & & & & \\
\hline Initially negative & $43 / 96(44.8 \%)$ & $64 / 96(66.7 \%)$ & & & & \\
\hline Converted from negative to positive & $13 / 43(30.2 \%)$ & $16 / 64(25.0 \%)$ & & & & \\
\hline Total positive & $66(68.7 \%)$ & $48(50.0 \%)$ & & & & \\
\hline Total negative & $30(31.2 \%)$ & $48(50.0 \%)$ & & & & \\
\hline Total patients in study* & $96(100 \%)$ & $96(100 \%)$ & & & & \\
\hline \multirow{2}{*}{$\begin{array}{l}\text { Cancer site data } \\
\text { Cut-off }\end{array}$} & \multicolumn{2}{|c|}{ CA72-4-Positive } & CA19-9-Positive & CA27-29-Positive & CEA-Positive & CA-125-Positive \\
\hline & $>0.8 \mathrm{U} / \mathrm{ml}$ & $>4 \mathrm{U} / \mathrm{ml}$ & $>35 \mathrm{U} / \mathrm{ml}$ & $>38.6 \mathrm{U} / \mathrm{ml}$ & $>5 \mathrm{U} / \mathrm{ml}$ & $>34.0 \mathrm{U} / \mathrm{ml}$ \\
\hline Breast & $8 / 12(67 \%)$ & $5 / 12(42 \%)$ & & $12 / 12(100 \%)$ & & \\
\hline Lung (adenocarcinoma) & $2 / 4(50 \%)$ & $0 / 4(0 \%)$ & & & $4 / 4(100 \%)$ & \\
\hline Colorectal, small bowel & $8 / 12(67 \%)$ & $5 / 12(42 \%)$ & & & $10 / 12(83 \%)$ & \\
\hline Ovarian & $18 / 28(64.3 \%)$ & $16 / 28(57 \%)$ & & & & $22 / 28(78.5 \%)$ \\
\hline Pancreatic & $27 / 33(82 \%)$ & $19 / 33(58 \%)$ & $28 / 33(84.8 \%)$ & & 9/33(\%) & \\
\hline Gallbladder/biliary/ampullary & $2 / 5(40 \%)$ & $2 / 5(40 \%)$ & $3 / 5(60 \%)$ & & $2 / 5(40 \%)$ & \\
\hline $\begin{array}{l}\text { Gastric/gastro-esophageal } \\
\text { junction/esophageal }\end{array}$ & $1 / 2(50 \%)$ & $1 / 2(50 \%)$ & & & $1 / 2(50 \%)$ & \\
\hline Total & $66 / 96(68.0 \%)$ & $48 / 96(50 \%)$ & $31 / 38(81.5 \%)$ & $12 / 12(100 \%)$ & $26 / 56(46.4 \%)$ & $22 / 28(78 \%)$ \\
\hline
\end{tabular}

*Two patients were excluded from the study/analysis (one with squamous cell lung cancer and one with sarcoma).

glycoprotein, with a half-life of approximately 7 days, was found to be expressed in gastrointestinal and mucosal tissue during fetal development but only minimally expressed in adult tissue $(15,16)$. Further studies showed that it was also overexpressed in adenocarcinomas of varying origin including gastric, hepatic, lung, pancreatic, ovarian and prostate (17-24). In colon cancer, the specificity and sensitivity of CEA has been shown to vary with advancing tumor stage, with specificity ranging between $37 \%$ and $86 \%$ in advanced disease, providing a useful means of monitoring disease (2527). CEA may also be elevated in benign conditions such as inflammatory bowel disease, pancreatitis and in smokers, limiting its utility in early-stage cancer and in patients with such conditions (28-31).

CA125. Encoded by the MUC16 gene, CA125 is a member of the mucin family of glycoproteins and is normally expressed in developing fetal epithelial lining of the body cavities and the female reproductive tract. The protein was first discovered by Dr. Robert Bast and other investigators at Harvard Medical School in 1981 after murine monoclonal antibodies were found to have reactivity with human epithelial ovarian carcinoma but not with non-malignant human tissues (32). CA125 is also associated with malignancies of the endometrium, fallopian tube, breast, lung, esophageal, gastric, hepatic and pancreatic cancers (3337). Elevations in CA125 have also been observed in non- malignant conditions such as during menses, late pregnancy, episodes of serosal irritation such as endometriosis, benign follicular ovarian cysts, and conditions associated with inflammation such as pelvic inflammatory disease, peritonitis, ascites, pericarditis and pleural effusions (38). CA125 expression has been found to be positive in up to $83 \%$ of patients with advanced epithelial ovarian cancer but only in $50 \%$ of patients with stage 1 disease, thus limiting its role in ovarian cancer screening in the general population.

CA19-9. CA19-9 has been validated as a serum tumor marker for patients with advanced pancreatic cancer. However, elevations have also been demonstrated in malignancies of the esophagus, stomach, gallbladder, biliary tract, and pancreas (39). Using $37 \mathrm{U} / \mathrm{ml}$ as cut-off for the upper limit of normal, sensitivity and specificity of $81 \%$ and $90 \%$ respectively have been reported in patients with pancreatic cancer with specificity increasing to almost $100 \%$ when a cut-off of $1,000 \mathrm{U} / \mathrm{ml}$ was used (3). Values over $1,000 \mathrm{U} / \mathrm{ml}$ also had implications in management and predicting response to therapy. For example, patients with a CA19-9 level greater than $1,000 \mathrm{U} / \mathrm{ml}$ at time of diagnosis were more likely to have unresectable disease (40). Biomarker analysis in large phase 3 pancreatic cancer trials showed that a decrease in CA19-9 by at least $90 \%$ correlated with increased survival (41-43). Prognostication studies by Reni et al. showed that the basal value of CA19-9 in 
advanced pancreatic disease correlated with survival $(44,45)$. Outcome analysis of CA19-9 nadir as a response to therapy affected overall survival, with patients showing survivals of 6.5, 10 and 16.7 months for an increase or decrease in CA199 of $<50 \%$, decrease by $50-89 \%$, and greater than $89 \%$ decrease, respectively. Additionally, a more recent study has also suggested that a decrease in CA19-9 by 8 weeks may be more predictive of survival compared to radiological response, making reliable tumor marker measurement an important tool in the management of patients (41).

Despite the usefulness of CA19-9 in monitoring pancreatic and biliary cancer, its overexpression in benign inflammatory conditions such as choledocholithiasis, acute and chronic pancreatitis, diverticulitis, Hashimoto's thyroiditis, rheumatoid arthritis and non-inflammatory conditions such as obstructive jaundice, ovarian cysts and heart failure may result in high false-positive rates of $10-30 \%$, limiting its usefulness in metastatic disease in patients with these conditions (46). Other limitations of CA19-9 include its dependence on fucosyltransferase for synthesis, an enzyme absent in up to $5 \%$ of the population, which is also required for human blood group Lewis antigen synthesis. As a result, measuring CA19-9 in patients with Lewis-null blood type may result in a potential false-negative result, further limiting its usefulness (47).

CA72-4. The tumor marker CA72-4 was first described by Dr. Jeffrey Schlom in the early 1980s as a novel antigen reactive to murine antibodies produced by mice that were immunized with membrane-enriched fractions of human metastatic mammary carcinoma cells (5). Of these, several monoclonal antibodies, including B72.3, were identified to have preferential binding to human carcinoma cells with sparing of normal adult tissues (5).

The advancement of monoclonal antibody testing in the late 1980s allowed continued development of novel identification techniques that facilitated further detection and characterization of CA72-4 (48). Initial studies showed elevation of CA72-4 in the sera of up to $40 \%$ of patients with colorectal and $42.6 \%$ of patients with gastric cancer, with increased levels being significant correlated with advanced stages of disease $(12,49)$. Additionally, it was found that approximately $50 \%$ of patients with colon cancer with undetectable CEA levels were in fact positive for CA72-4. Longitudinal studies of postoperative patients that did not have initial elevation of CEA in blood showed there to be an early rise in CA72-4 before clinical manifestation of recurrent disease (50). In 1994, study to further characterize the utility of CA72-4 by investigators at Massachusetts General Hospital showed that CA72-4 was differentially expressed in both benign and malignant pancreatic cystic lesions (51). Of 19 patients with uncharacterized pancreatic cysts, fluid aspirations revealed that intra-cystic CA72-4 levels were elevated in all five patients with cystadenocarcinomas, with a mean CA72-4 level of over $10,000 \mathrm{U} / \mathrm{ml}$, compared to $3.8 \mathrm{U} / \mathrm{ml}$ in patients with pseudocysts, $<3 \mathrm{U} / \mathrm{ml}$ in tuw serous cystadenomas and $44.2 \mathrm{U} / \mathrm{ml}$ in those with benign mucinous cystic neoplasms. CA72-4 in pancreatic cyst fluid was seen as a promising new marker for the differentiation of mucinous cystadenocarcinomas from pseudocysts, with intermediate CA72-4 levels suggesting the presence of benign mucinous cystic neoplasms (51). More recently, pre-operative evaluation of CA72-4 in patients with gastric cancer showed a correlation between serum CA72-4 levels and presence of lymph node metastasis, while elevations in peritoneal fluid corresponded with both $\mathrm{T}$ and $\mathrm{N}$ stage of disease (52), (53) suggesting a possible role in the staging of certain gastrointestinal malignancies.

Despite these early studies indicating a possible role of CA72-4 in the monitoring of advanced disease, testing for CA72-4 has not been widely adopted in the United States. Studies conducted on Japanese and East Asian patients with gastrointestinal malignancies combining CA72-4 with CEA and CA19-9 has shown useful disease correlation, with sensitivity of up to $74 \%$ without impairing specificity (54). Detectable levels of CA72-4 have also been found in patients with tumor of multiple origins including cancer of the lung (36\%), ovary (24\%, of which more than half had stage IV disease), and colon (40\%) (50). Sensitivity of up to $40 \%$ in patients with colorectal and gastric carcinomas and $50 \%$ in ovarian cancer, with an overall specificity of over $95 \%$, have been reported (55). Additionally, mathematical models combining pre-operative serum tumor biomarker measurements have shown a further increase in sensitivity and specificity in the detection of early-stage ovarian cancer, demonstrating clinical value in combinational analysis of multiple biomarkers in patients with ovarian cancer (56). Measurement of CA72-4 has also shown good correlation with disease burden and is predictive of disease recurrence (50).

In our study, we employed an ELISA-based method that can be used in an outpatient laboratory or hospital setting to reliably measure the CA72-4 level of patients with various malignancies. While several ELISA-based assays for detection of CA72-4 are already currently available and in active clinical use, it has only garnered approval in countries outside of North America. Our study supports the potential use and role of CA72-4 in disease monitoring and surveillance in various gastrointestinal and gynecologic malignancies, particularly of pancreatic and ovarian origin, in a North American population. We found that the rate of positivity of CA72-4 in pancreatic cancer at a level of detection cut-off of $0.8 \mathrm{U} / \mathrm{ml}$, was comparable to the FDAapproved CA19-9 in our cohort, $82 \%$ versus $85 \%$ respectively, using the CC-49 antibody ELISA assay. Increasing the detection threshold to $4 \mathrm{U} / \mathrm{ml}$ as described in previously reported studies reduced the positivity rate to 
$58 \%$. We also found that CA72-4 was elevated in approximately $64 \%$ of those with advanced ovarian malignancies, while corroborating existing positivity rates of approximately $80 \%$ for CA125 in the same population.

A specific example of concordance of the CA72-4 level with CA19-9 in clinical outcome and response to therapy is illustrated by a 60 -year-old patient with metastatic pancreatic cancer. This patient initially exhibited a decline in both CA199 and CA72-4 levels, this correlated with clinical and radiological response after initiation of systemic chemotherapy. Both biomarkers remained stable for approximately 6 months, after which an increase in CA72-4 $(0.8 \mathrm{U} / \mathrm{ml}$ to $4.6 \mathrm{U} / \mathrm{ml})$ and CA19-9 (177 U/ml to $1734 \mathrm{U} / \mathrm{ml})$ was detected, indicating disease progression. A continued rise in both biomarkers was noted, with CA72-4 and CA19-9 levels peaking at 15 and 30 times their baseline level, respectively, at the time of death. While clinical outcomes in our study were based on investigator's assessment, future studies with standardized measures such as RECIST criteria, and health-related quality of life instruments may ensure more accurate results.

Another example of utility of CA72-4 is in patients with pancreatic cancer who do not express CA19-9. This is exemplified by a 67-year-old with widespread metastatic pancreatic cancer with a normal level of CA19-9 despite huge tumor burden. This patient continued to have a normal level of CA19-9 throughout her clinical course which correlated with the level of CA72-4. Interestingly, she was found to be blood type A-positive, an unexpected finding since fucosylation that is required for CA19-9 production as well as Lewis antigen synthesis is not known to be affected in patients of this blood group.

On a cautionary note, CA72-4 may be transiently and falsely elevated in some patients with biliary obstruction. An example of this was that of a patient with advanced pancreatic cancer causing biliary obstruction with a marked elevation of CA19-9 at presentation. The patient underwent biliary stent placement followed by chemotherapy, with resultant decrease in CA19-9. Three months later, an abrupt increase in CA72-4 level ( $2 \mathrm{U} / \mathrm{ml}$ to $14.53 \mathrm{U} / \mathrm{ml}$ ) was noted. Abdominal imaging revealed stent migration causing recurrent biliary obstruction which required stent exchange. A decrease in CA72-4 was observed with continued normalization of values. Interestingly, the patient's CA19-9 level was unaffected and continued to decline in the setting of biliary obstruction, reinforcing the importance and potential value in combination testing of CA19-9 and CA724 in patients prone to biliary obstruction.

In conclusion, through this prospective study we demonstrated that the level of tumor marker CA72-4 varies in different metastatic cancers of gastrointestinal and gynecologic origin, with the highest positivity rates found in pancreatic, ovarian and colorectal carcinomas. This multiyear study, despite its limited sample size, demonstrates that
CA72-4 has meaningful correlation with disease activity and may potentially be a useful adjunct to conventional biomarkers in monitoring of various gastrointestinal and gynecologic malignancies.

\section{Conflicts of Interest}

The Authors have declared no conflict of interest or financial disclosures in regard to the study.

\section{Acknowledgements}

The methodology for the ELISA assay used in the study was developed by DRG International, Inc (NJ, USA). The study was supported in part by DRG International, who provided us with the ELISA Kits, reagents, ELISA Instrument, and gave financial support for technician time to run the assays.

\section{References}

1 Chen DX, Schwartz PE, Li XG and Yang Z: Evaluation of ca 125 levels in differentiating malignant from benign tumors in patients with pelvic masses. Obstet Gynecol 72(1): 23-27, 1988.

2 Tuxen MK, Soletormos G and Dombernowsky P: Serum tumor marker CA 125 for monitoring ovarian cancer during follow-up. Scand J Clin Lab Invest 62(3): 177-188, 2002.

3 Steinberg W: The clinical utility of the CA 19-9 tumorassociated antigen. Am J Gastroenterol 85(4): 350-355, 1990.

4 Fletcher RH: Carcinoembryonic antigen. Ann Intern Med 104(1): 66-73, 1986.

5 Colcher D, Hand PH, Nuti M and Schlom J: A spectrum of monoclonal antibodies reactive with human mammary tumor cells. Proc Natl Acad Sci USA 78(5): 3199-3203, 1981.

6 Sheer DG, Schlom J and Cooper HL: Purification and composition of the human tumor-associated glycoprotein (TAG72) defined by monoclonal antibodies cc 49 and b72.3. Cancer Res 48(23): 6811-6818, 1988.

7 Thor A, Ohuchi N, Szpak CA, Johnston WW and Schlom J: Distribution of oncofetal antigen tumor-associated glycoprotein72 defined by monoclonal antibody B72.3. Cancer Res 46(6): 3118-3124, 1986.

8 Thor A, Viglione MJ, Muraro R, Ohuchi N, Schlom J and Gorstein F: Monoclonal antibody B72.3 reactivity with human endometrium: A study of normal and malignant tissues. Int J Gynecol Pathol 6(3): 235-247, 1987.

9 Nuti M, Teramoto YA, Mariani-Costantini R, Hand PH, Colcher $\mathrm{D}$ and Schlom J: A monoclonal antibody (b72.3) defines patterns of distribution of a novel tumor-associated antigen in human mammary carcinoma cell populations. Int J Cancer 29(5): 539545, 1982.

10 Mattar R, Alves de Andrade CR, DiFavero GM, Gama-Rodrigues JJ and Laudanna AA: Preoperative serum levels of CA 72-4, CEA, CA 19-9, and alpha-fetoprotein in patients with gastric cancer. Rev Hosp Clin Fac Med Sao Paulo 57(3): 89-92, 2002.

11 Louhimo J, Carpelan-Holmstrom M, Alfthan H, Stenman UH, Jarvinen HJ and Haglund C: Serum hcg beta, CA 72-4 and CEA are independent prognostic factors in colorectal cancer. Int $\mathrm{J}$ Cancer 101(6): 545-548, 2002. 
12 Guadagni F, Roselli M, Amato T, Cosimelli M, Perri P, Casale V, Carlini M, Santoro E, Cavaliere R, Greiner JW and Schlom J: CA 72-4 measurement of tumor-associated glycoprotein 72 (TAG-72) as a serum marker in the management of gastric carcinoma. Cancer Res 52(5): 1222-1227, 1992.

13 Perkins GL, Slater ED, Sanders GK and Prichard JG: Serum tumor markers. Am Fam Physician 68(6): 1075-1082, 2003.

14 Gold P and Freedman SO: Demonstration of tumor-specific antigens in human colonic carcinomata by immunological tolerance and absorption techniques. J Exp Med 121: 439-462, 1965.

15 Gold P and Freedman SO: Specific carcinoembryonic antigens of the human digestive system. J Exp Med 122(3): 467-481, 1965.

16 Wagener C, Hain F, Fodisch HJ and Breuer H: Localisation of carcinoembryonic antigen in embryonic and fetal human tissues. Histochemistry 78(1): 1-9, 1983.

17 Nan J, Li J, Li X, Guo G, Wen X and Tian Y: Preoperative serum carcinoembryonic antigen as a marker for predicting the outcome of three cancers. Biomark Cancer 9: 1-7, 2017.

18 Uda H, Kanda M, Tanaka C, Kobayashi D, Inaoka K, Tanaka Y, Hayashi M, Iwata N, Yamada S, Fujii T, Sugimoto H, Murotani $\mathrm{K}$, Fujiwara $\mathrm{M}$ and Kodera $\mathrm{Y}$ : Perioperative serum carcinoembryonic antigen levels predict recurrence and survival of patients with pathological t2-4 gastric cancer treated with curative gastrectomy. Dig Surg, 2017. doi: 10.1159/000471931. [Epub ahead of print]

19 Wada N, Kurokawa Y, Miyazaki Y, Makino T, Takahashi T, Yamasaki M, Nakajima K, Takiguchi S, Mori M and Doki Y: The characteristics of the serum carcinoembryonic antigen and carbohydrate antigen 19-9 levels in gastric cancer cases. Surg Today 47(2): 227-232, 2017.

20 Yoshikawa M, Morine Y, Ikemoto T, Imura S, Higashijima J, Iwahashi S, Saito YU, Takasu C, Yamada S, Ishikawa D, Teraoku H, Takata A, Yoshimoto T and Shimada M: Elevated preoperative serum cea level is associated with poor prognosis in patients with hepatocellular carcinoma through the epithelialmesenchymal transition. Anticancer Res 37(3): 1169-1175, 2017.

21 Jin X, Xu X, Xu H, Lv L and Lu H: The diagnostic value of carcinoembryonic antigen and squamous cell carcinoma antigen in lung adenosquamous carcinoma. Clin Lab 63(4): 801-808, 2017.

22 Nishio R, Furuya Y, Nagakawa O and Fuse H: Metastatic prostate cancer with normal level of serum prostate-specific antigen. Int Urol Nephrol 35(2): 189-192, 2003.

23 Sagi-Dain L, Lavie O, Auslander R and Sagi S: CEA in evaluation of adnexal mass: Retrospective cohort analysis and review of the literature. Int J Biol Markers 30(4): e394-400, 2015.

24 Luo G, Liu C, Guo M, Cheng H, Lu Y, Jin K, Liu L, Long J, Xu $\mathrm{J}, \mathrm{Lu} \mathrm{R}, \mathrm{Ni} \mathrm{Q}$ and Yu X: Potential biomarkers in lewis negative patients with pancreatic cancer. Ann Surg 265(4): 800-805, 2017.

25 Moertel CG, O'Fallon JR, Go VL, O'Connell MJ and Thynne GS: The preoperative carcinoembryonic antigen test in the diagnosis, staging, and prognosis of colorectal cancer. Cancer 58(3): 603-610, 1986.

26 Hundt S, Haug U and Brenner H: Blood markers for early detection of colorectal cancer: A systematic review. Cancer Epidemiol Biomarkers Prev 16(10): 1935-1953, 2007.

27 Tomasevic R, Milosavljevic T, Stojanovic D, Gluvic Z, Dugalic P, Ilic I and Vidakovic R: Predictive value of carcinoembryonic and carbohydrate antigen 19-9 related to some clinical, endoscopic and histological colorectal cancer characteristics. J Med Biochem 35(3): 324-332, 2016.
28 Go VL: Carcinoembryonic antigen: Clinical application. Cancer 37(1 suppl): 562-566, 1976.

29 Silverman NA, Alexander JC Jr. and Chretien PB: CEA levels in head and neck cancer. Cancer 37(5): 2204-2211, 1976.

30 Mittal A, Farooqui SM, Pyrtuh S, Poudel B, Sathian B and Yadav SK: Efficacy of carcinogenic embryonic antigen in differential diagnosis of diseases of pancreas and liver-a comparative study in a tertiary care hospital of western nepal. Asian Pac J Cancer Prev 13(1): 275-277, 2012.

31 Loewenstein MS and Zamcheck N: Carcinoembryonic antigen (CEA) levels in benign gastrointestinal disease states. Cancer 42(3 Suppl): 1412-1418, 1978.

32 Bast RC Jr., Feeney M, Lazarus H, Nadler LM, Colvin RB and Knapp RC: Reactivity of a monoclonal antibody with human ovarian carcinoma. J Clin Invest 68(5): 1331-1337, 1981.

33 Hefler LA, Rosen AC, Graf AH, Lahousen M, Klein M, Leodolter S, Reinthaller A, Kainz C and Tempfer CB: The clinical value of serum concentrations of cancer antigen 125 in patients with primary fallopian tube carcinoma: A multicenter study. Cancer 89(7): 1555-1560, 2000.

34 Salgia R, Harpole D, Herndon JE, 2nd, Pisick E, Elias A and Skarin AT: Role of serum tumor markers CA 125 and CEA in non-small cell lung cancer. Anticancer Res 21(2B): 1241-1246, 2001.

35 Lakshmanan I, Ponnusamy MP, Das S, Chakraborty S, Haridas D, Mukhopadhyay P, Lele SM and Batra SK: Muc16 induced rapid $\mathrm{G}_{2} / \mathrm{M}$ transition via interactions with JAK2 for increased proliferation and anti-apoptosis in breast cancer cells. Oncogene 31(7): 805-817, 2012.

36 Haglund C, Kuusela P, Roberts P and Jalanko H: Tumour marker CA 125 in patients with digestive tract malignancies. Scand J Clin Lab Invest 51(3): 265-270, 1991.

37 Streppel MM, Vincent A, Mukherjee R, Campbell NR, Chen SH, Konstantopoulos K, Goggins MG, Van Seuningen I, Maitra A and Montgomery EA: Mucin 16 (cancer antigen 125) expression in human tissues and cell lines and correlation with clinical outcome in adenocarcinomas of the pancreas, esophagus, stomach, and colon. Hum Pathol 43(10): 1755-1763, 2012.

38 Meden $\mathrm{H}$ and Fattahi-Meibodi A: CA 125 in benign gynecological conditions. Int J Biol Markers 13(4): 231-237, 1998.

39 Passerini R, Cassatella MC, Boveri S, Salvatici M, Radice D, Zorzino L, Galli C and Sandri MT: The pitfalls of CA19-9: Routine testing and comparison of two automated immunoassays in a reference oncology center. Am J Clin Pathol 138(2): 281287, 2012.

40 Liu L, Xu H, Wang W, Wu C, Chen Y, Yang J, Cen P, Xu J, Liu C, Long J, Guha S, Fu D, Ni Q, Jatoi A, Chari S, McClearyWheeler AL, Fernandez-Zapico ME, Li M and Yu X: A preoperative serum signature of CEA+/CA125+/CA19-9 $\geq 1000$ $\mathrm{U} / \mathrm{ml}$ indicates poor outcome to pancreatectomy for pancreatic cancer. Int J Cancer 136(9): 2216-2227, 2015.

41 Chiorean EG, Von Hoff DD, Reni M, Arena FP, Infante JR, Bathini VG, Wood TE, Mainwaring PN, Muldoon RT, Clingan PR, Kunzmann V, Ramanathan RK, Tabernero J, Goldstein D, McGovern D, Lu B and Ko A: CA19-9 decrease at 8 weeks as a predictor of overall survival in a randomized phase III trial (MPACT) of weekly nab-paclitaxel plus gemcitabine versus gemcitabine alone in patients with metastatic pancreatic cancer. Ann Oncol 27(4): 654-660, 2016. 
42 Yang GY, Malik NK, Chandrasekhar R, Ma WW, Flaherty L, Iyer R, Kuvshinoff B, Gibbs J, Wilding G, Warren G and May KS: Change in CA 19-9 levels after chemoradiotherapy predicts survival in patients with locally advanced unresectable pancreatic cancer. J Gastrointest Oncol 4(4): 361-369, 2013.

43 Ziske C, Schlie C, Gorschluter M, Glasmacher A, Mey U, Strehl J, Sauerbruch T and Schmidt-Wolf IG: Prognostic value of CA 19-9 levels in patients with inoperable adenocarcinoma of the pancreas treated with gemcitabine. Br J Cancer 89(8): 14131417, 2003.

44 Reni M, Cereda S, Balzano G, Passoni P, Rognone A, Fugazza C, Mazza E, Zerbi A, Di Carlo V and Villa E: Carbohydrate antigen 19-9 change during chemotherapy for advanced pancreatic adenocarcinoma. Cancer 115(12): 2630-2639, 2009.

45 Maisey NR, Norman AR, Hill A, Massey A, Oates J and Cunningham D: CA19-9 as a prognostic factor in inoperable pancreatic cancer: The implication for clinical trials. Br J Cancer 93(7): 740-743, 2005.

46 Ballehaninna UK and Chamberlain RS: The clinical utility of serum CA 19-9 in the diagnosis, prognosis and management of pancreatic adenocarcinoma: An evidence based appraisal. J Gastrointest Oncol 3(2): 105-119, 2012.

47 Kannagi R: Carbohydrate antigen sialyl Lewis a - its pathophysiological significance and induction mechanism in cancer progression. Chang Gung Med J 30(3): 189-209, 2007.

48 Paterson AJ, Schlom J, Sears HF, Bennett J and Colcher D: A radioimmunoassay for the detection of a human tumorassociated glycoprotein (TAG-72) using monoclonal antibody B72.3. Int J Cancer 37(5): 659-666, 1986.

49 Ohuchi N, Takahashi K, Matoba N, Sato T, Taira Y, Sakai N, Masuda M and Mori S: Comparison of serum assays for TAG72, CA19-9 and CEA in gastrointestinal carcinoma patients. Jpn J Clin Oncol 19(3): 242-248, 1989.

50 Guadagni F, Roselli M, Amato T, Cosimelli M, Mannella E, Tedesco M, Grassi A, Casale V, Cavaliere F, Greiner JW and Schlom J: Clinical evaluation of serum tumor-associated glycoprotein-72 as a novel tumor marker for colorectal cancer patients. J Surg Oncol Suppl 2: 16-20, 1991.
51 Alles AJ, Warshaw AL, Southern JF, Compton CC and Lewandrowski KB: Expression of CA 72-4 (TAG-72) in the fluid contents of pancreatic cysts. A new marker to distinguish malignant pancreatic cystic tumors from benign neoplasms and pseudocysts. Ann Surg 219(2): 131-134, 1994.

$52 \mathrm{Li} \mathrm{F}$, Li S, Wei L, Liang X, Zhang H and Liu J: The correlation between pre-operative serum tumor markers and lymph node metastasis in gastric cancer patients undergoing curative treatment. Biomarkers 18(7): 632-637, 2013.

53 Yamamoto M, Yoshinaga K, Matsuyama A, Tsutsui S and Ishida T: CEA/CA72-4 levels in peritoneal lavage fluid are predictive factors in patients with gastric carcinoma. J Cancer Res Clin Oncol 140(4): 607-612, 2014.

54 Chen XZ, Zhang WK, Yang K, Wang LL, Liu J, Wang L, Hu JK, Zhang B, Chen ZX, Chen JP, Zhou ZG and Mo XM: Correlation between serum CA724 and gastric cancer: Multiple analyses based on Chinese population. Mol Biol Rep 39(9): 9031-9039, 2012.

55 Guadagni F, Roselli M, Cosimelli M, Ferroni P, Spila A, Cavaliere F, Casaldi V, Wappner G, Abbolito MR, Greiner JW and Schlom J: CA 72-4 serum marker-a new tool in the management of carcinoma patients. Cancer Invest 13(2): 227238, 1995.

56 Skates SJ, Horick N, Yu Y, Xu FJ, Berchuck A, Havrilesky LJ, de Bruijn HW, van der Zee AG, Woolas RP, Jacobs IJ, Zhang Z and Bast RC Jr.: Preoperative sensitivity and specificity for early-stage ovarian cancer when combining cancer antigen CA125II, CA 15-3, CA 72-4, and macrophage colony-stimulating factor using mixtures of multivariate normal distributions. J Clin Oncol 22(20): 4059-4066, 2004.
Received May 1, 2017

Revised May 16, 2017

Accepted May 19, 2017 